\title{
非贵金属电催化
}

\author{
张铁锐 1 , 王双印 2 \\ 1 中国科学院理化技术研究所, 中国科学院光化学转换与功能材料重点实验室, 北京 100190 \\ 2 湖南大学化学化工学院, 化学生物传感与计量学国家重点实验室, 长沙 410082
}

\section{Noble-Metal-Free Electrocatalysis}

\section{Tierui Zhang ${ }^{1}$, Shuangyin Wang ${ }^{2}$}

${ }^{1}$ Key Laboratory of Photochemical Conversion and Optoelectronic Materials, Technical Institute of Physics and Chemistry, Chinese Academy of Sciences, Beijing 100190, China.

${ }^{2}$ State Key Laboratory of Chem/Bio-Sensing and Chemometrics, College of Chemistry and Chemical Engineering, Hunan University, Changsha 410082, China.

Emails: tierui@mail.ipc.ac.cn (T.Z.); shuangyinwang@hnu.edu.cn (S.W.)

Published online: December 23, 2020.

先进的电催化体系是实现高效电能-化学能 相互转换的核心。在绿色氢能、燃料电池和人工碳 循环等领域, 涉及多种典型的电极反应(包括水分 解、氧还原和二氧化碳还原等)。而电极的组成部 分之一, 即驱动电化学反应所需的电催化材料, 通 常是决定电催化体系效能的关键。因此, 电催化材 料的组分、结构及界面特性成为了整个电化学学 科的研究重点。在电催化材料的设计开发中, 贵金 属(如Pt、Pd、Ir等)通常具有较高的催化活性。但 受限于极低的地壳丰度以及极高的原料成本, 贵 金属催化剂无法满足大规模实际生产的需求。因 此, 采用非贵金属电催化材料, 以期降低电极中贵 金属组分的用量, 抑或完全取代贵金属材料, 具有 重要的现实意义。

非贵金属材料来源十分广泛，既可以是廉价 的过渡金属(如Fe、 $\mathrm{Ni} 、 \mathrm{Mn}$ 等)单质或化合物(氧化 物、氮化物、磷化物等), 也可以是碳基非金属材 料(如石墨烯、碳量子点、有机框架结构等), 这意 味着非贵金属电催化的研究前景十分广阔。前期 研究显示, 非贵金属催化材料的电化学活性以及 稳定性通常明显低于贵金属催化材料, 尤其在能 源相关的电催化反应中仍然面临巨大挑战。非贵 金属电催化性质的提升依赖于对其材料组分、结 构的进一步设计与调控。本专刊中收集了国内部 分电催化领域科学家的优秀研究成果, 重点报道
了一系列非贵金属电催化材料的合成、改性以及 构效关系的最新研究进展, 讨论了非贵金属催化 材料在降低催化反应过电势、创新电极反应类型、 实现较低电催化综合运行成本(材料成本、电力成 本及时间成本)等方面的潜在优势。

电解水制氢具有反应条件温和、氢气纯度高、 原料及副产物清洁(水和氧气)等优点, 因此一直是 电催化领域的研究热点之一。然而, 目前该反应的 实际应用依然受限于较高的制氢成本。解决思路 之一就是不断优化调控非贵金属催化材料的组分 结构, 降低电解水析氢、析氧半反应的过电势, 提 升大电流密度下的电能利用效率。在催化材料选 择方面, 苏东 ${ }^{1}$ 及木士春 ${ }^{2}$ 等分别论述了基于廉价过 渡金属元素的高熵合金以及金属氮化物在电解水 析氢、析氧等重要电极反应中的催化反应机制与 潜在应用价值。碳量子点作为一类合成方法简便、 化学稳定性好、电子传导性能优异的无机碳材料, 被广泛应用于电催化载体材料的构筑。卢思宇等 3 将钉纳米颗粒与碳量子点相结合, 利用碳量子点 与金属离子配位形成的空间限域作用, 有效提高 了钉纳米颗粒的分散性, 从而使得活性位点充分 暴露, 电催化析氢的过电势仅为 $22 \mathrm{mV}$ 。此外, 张 伟等 ${ }^{4}$ 设计了一种基于磷酸锰的仿生材料, 模拟了 自然界光合系统II中的析氧中心外围结构, 促进了 质子的转移过程, 在中性条件下表现出了较高的 
电催化析氧活性。

降低电催化成本的另一条解决思路是设计双 功能电催化材料, 以期将一种催化材料同时应用 于电解池(或燃料电池)的氧化与还原电极反应中。 金属有机框架结构(MOF)具有丰富可调的拓扑结 构、较大的比表面积以及多孔特性。张志成 5 、黄 小青6等系统论述了近期关于非贵金属有机框架 材料的结构设计, 及其在电催化中面临的机遇与 挑战。杨小飞等7设计了一种金属有机框架衍生的 棒状多孔碳负载镍纳米颗粒, 在电催化分解水析 氢及析氧反应中分别得到了 $120 \mathrm{mV}$ 及 $350 \mathrm{mV}$ 的 过电势, 显示出了这种电催化材料优异的双功能 特性。此外, 电催化分解水析氧反应及氧还原反 应, 是金属-空气电池中的放电与充电过程的电极 反应基础。由于这两种反应需要在同一侧电极发 生, 其对于双功能电催化材料的依赖程度更高。王 家成等 ${ }^{8}$ 采用一步热解法, 将磷化钴纳米颗粒封装 于磷掺杂多孔碳材料中, 显示出与商业铂碳相当 的充放电半波电位, 以及更好的锌-空气电池比容 量和运行稳定性。

在研究传统电化学过程的基础上, 对电极反 应进行创新, 能够有益于电池能耗的降低、产物附 加值的提升以及电催化应用领域的拓展。非贵金 属电催化材料的多样性恰好为电极反应的创新提 供了所需的材料学研究平台。欧阳述昕等 ${ }^{9}$ 将镍基 金属有机框架结构进行碳化处理, 得到了一种负 载有镍纳米颗粒的碳基棒状结构, 实现了甲醇电 化学氧化制甲酸反应的有效进行。作为传统电解 水析氧反应的替代反应, 不仅能够降低电催化制 氢的电力成本, 还可以有效提升对电极产物的附 加值。符显珠等 ${ }^{10}$ 在固体氧化物燃料电池的研究 中, 通过钴铁合金与氧化铈的协同作用, 在达到较 高功率密度的基础上, 将乙烷高选择性地催化转 化为乙烯, 成功实现了燃料电池发电与乙烯合成 体系的共生。近年来, 电催化氮气还原合成氨作为 最有代表性的电极反应创新之一, 得到了极大的 关注。廉价过渡金属是工业合成氨催化材料的主 要组成部分, 因此基于过渡金属的电催化合成氨 材料研究, 是近期该领域的研究热点。但亦如前文 所述, 过渡金属材料同样具有出色的电解水析氢 性质, 因此极易形成阴极反应竞争, 不利于电催化 合成氨反应的有效进行。孙旭平等 ${ }^{11}$ 系统总结了碳 基、嗍基和磷基非金属材料在电催化合成氨中的 研究进展, 并对其在促进氮气分子吸附、抑制竞争 反应等方面的潜在优势进行了详细介绍。此外, 另 一种电解水析氢反应的替代方案, 即电催化二氧
化碳还原, 同样得到了广泛研究, 近两年在电极能 量转换效率、产物法拉第效率等方面取得了突破 性研究进展, 并且在非贵金属材料选择方面呈现 出百花齐放的态势。孙振宇等 ${ }^{12}$ 总结了铜、锡、钴、 铋、铟、锌等氧化物材料在电催化二氧化碳还原反 应中的最新研究进展, 并对非贵金属氧化物基电 催化材料的未来发展方向进行了展望。

可以预见，电催化技术将在未来十年间取得 更多突破。而非贵金属催化材料需要进一步应对 其在电化学活性、催化选择性以及运行稳定性等 方面存在的诸多科学挑战, 方能在电解水制氢、二 氧化碳还原、燃料电池等诸多电催化应用中扮演 更加重要的角色。

\section{References}

(1) Zhao, K.; Li, X.; Su, D. Acta Phys. -Chim. Sin. 2021, 37 (7), 2009077. [赵康宁, 李潇, 苏东. 物理化学学报, 2021, 37 (7), 2009077.] doi: 10.3866/PKU.WHXB202009077

(2) Qin, R.; Wang, P.; Lin, C.; Cao, F.; Zhang, J.; Chen, L.; Mu, S. Acta Phys. -Chim. Sin. 2021, 37 (7), 2009099. [秦睿, 王鹏彦, 林灿, 曹 菲, 张金咏, 陈否, 木士春. 物理化学学报, 2021, 37 (7), 2009099.] doi: 10.3866/PKU.WHXB202009099

(3) Liu, Y.; Li, W.; Wu, H.; Lu, S. Acta Phys. -Chim. Sin. 2021, 37 (7), 2009082. [刘源, 李卫东, 吴捍, 卢思宇. 物理化学学报, 2021, 37 (7), 2009082.] doi: 10.3866/PKU.WHXB202009082

(4) Gao, X.; Yang, S.; Zhang, W.; Cao, R. Acta Phys. -Chim. Sin. 2021, 37 (7), 2007031. [高学庆, 杨树姣, 张伟, 曹睿. 物理化学学报, 2021, 37 (7), 2007031.] doi: 10.3866/PKU.WHXB202007031

(5) Gao, Z.; Wang, C.; Li, J.; Zhu, Y.; Zhang, Z.; Hu, W. Acta Phys. -Chim. Sin. 2021, 37 (7), 2010025. [高增强, 王聪勇, 李俊俊, 朱亚廷, 张志成, 胡文平. 物理化学学报, 2021, 37 (7), 2010025.] doi: 10.3866/PKU.WHXB202010025

(6) Xu, B.; Zhang, Y.; Pi, Y.; Shao, Q.; Huang, X. Acta Phys. -Chim. Sin. 2021, 37 (7), 2009074. [徐冰妍, 张应, 皮业灿, 邵琪, 黄小青. 物理化学学报, 2021, 37 (7), 2009074.] doi: 10.3866/PKU.WHXB202009074

(7) Yan, D.; Zhang, L.; Chen, Z.; Xiao, W.; Yang, X. Acta Phys. -Chim. Sin. 2021, 37 (7), 2009054. [闵大强, 张林, 陈祖鹏, 肖卫平, 杨小 飞. 物理化学学报, 2021, 37 (7), 2009054.] doi: 10.3866/PKU.WHXB202009054

(8) Xiao, Y.; Pei, Y.; Hu, Y.; Ma, R.; Wang, D.; Wang, J. Acta Phys. -Chim. Sin. 2021, 37 (7), 2009051. [肖瑶, 裴煜, 胡一帆, 马汝广, 王德义, 王家成. 物理化学学报, 2021, 37 (7), 2009051.] doi: 10.3866/PKU.WHXB202009051

(9) Lv, L.; Zhang, L.; He, X.; Yuan, H.; Ouyang, S.; Zhang, T. Acta Phys. -Chim. Sin. 2021, 37 (7), 2007079. [吕琳, 张立阳, 何雪冰, 
原弘, 欧阳述昕, 张铁锐. 物理化学学报, 2021, 37 (7), 2007079.] doi: 10.3866/PKU.WHXB202007079

(10) Fan, Y.; Chen, G.; Xi, X.; Li, J.; Wang, Q.; Luo, J.; Fu, X. Acta Phys. -Chim. Sin. 2021, 37 (7), 2009107. [樊望，陈国诞，奚修安， 李俊, 王琦, 骆静利, 符显珠. 物理化学学报, 2021, 37 (7), 2009107.] doi: 10.3866/PKU.WHXB202009107

(11) Xu, T.; Ma, B.; Liang, J.; Yue, L.; Liu, Q.; Li, T.; Zhao, H.; Luo, Y.;
Lu, S.; Sun, X. Acta Phys. -Chim. Sin. 2021, 37 (7), 2009043. [许桐, 马奔原, 梁杰, 岳鲁超, 刘倩, 李廷帅, 赵海涛, 罗永嵩, 卢思宇, 孙旭平. 物理化学学报, 2021, 37 (7), 2009043.] doi: 10.3866/PKU.WHXB202009043

(12) Hao, L.; Sun, Z. Acta Phys. -Chim. Sin. 2021, 37 (7), 2009033. [郝否端, 孙振宇. 物理化学学报, 2021, 37 (7), 2009033.] doi: 10.3866/PKU.WHXB202009033 